\title{
Predicting left ventricular dyssynchrony: Can nuclear cardiology bring us closer "In Sync"?
}

\author{
Karen Kan, MD, a and Lawrence M. Phillips, MD, FASNC ${ }^{\mathrm{a}}$ \\ a The Leon H. Charney Division of Cardiology, NYU Langone Health, New York
}

Received Jun 2, 2020; accepted Jun 2, 2020

doi: $10.1007 / \mathrm{s} 12350-020-02226-w$

\section{See related article, pp. 1140-1150}

Multiple imaging modalities including baseline electrocardiography and echocardiography have been investigated for independent prediction of left ventricular mechanical dyssynchrony (LVMD). This cardiac finding is extremely important given the impact that it has both on worsening of cardiac status as well as treatment focus. Cardiac resynchronization therapy (CRT) is a Class I indication for patients with advanced heart failure and the following criteria: severely depressed left ventricular ejection fraction $(\leq 35 \%)$, left bundle branch block (LBBB) with wide QRS duration on electrocardiogram ( $\geq 150 \mathrm{~ms}$ ), and New York Heart Association (NYHA) class II, III, or IV symptoms. ${ }^{1}$ Although improvement in functional status and quality of life is seen in many patients, it has been reported that up to $30 \%$ of patients who meet AHA/ACC guidelines for implantation of CRT fail to respond. ${ }^{2-5}$ However, what is missing from the patient profile above is confirmation of LVMD. It has been observed that patients demonstrating LVMD are more likely to respond favorably to CRT suggesting that perhaps more refined criteria may be needed to predict which subset of patients will benefit from CRT. ${ }^{6,7}$ It has also been demonstrated that LVMD may exist in patients with right bundle branch block (RBBB) who may not fulfill the typical criteria for CRT implantation, but who may nevertheless, benefit from resynchronization. ${ }^{8,9}$ Prior studies have shown that LVMD can be accurately evaluated by gated single-photon emission computed

Reprint requests: Lawrence M. Phillips, MD, FASNC, The Leon H. Charney Division of Cardiology, NYU Langone Health, New York; lawrence.phillips@nyumc.org

J Nucl Cardiol 2021;28:1151-2.

1071-3581/\$34.00

Copyright (C) 2020 American Society of Nuclear Cardiology. tomography (SPECT) myocardial perfusion imaging (MPI) ${ }^{10,11}$ However, the exact pathogenesis of LVMD remains poorly understood.

In this issue of the Journal of Nuclear Cardiology, Sillanmäki and colleagues bring us further "in sync" with the potential mechanisms responsible for LVMD. ${ }^{12}$ The study authors investigated the relative contribution of QRS duration on electrocardiogram, left ventricular ejection fraction (LVEF), end-systolic and end-diastolic volumes as well as the presence of scar on abnormal phase bandwidth (PhaseBW). The study was conducted as a retrospective analysis of SPECT MPI data of 358 total patients with conduction abnormalities including 275 LBBB and 83 RBBB patients from three international sites (US, Italy, and Finland). Hospital and gender-specific normal values were obtained from 172 controls. LVMD was observed in $85 \%$ of LBBB patients and $40 \%$ of RBBB patients (as defined as abnormal phase bandwith (BW) or phase standard deviation (SD)). In the authors' multivariable model, left ventricular ejection fraction was independently associated with LVMD and explained $63 \%$ of variance seen in PhaseBW; moreover, EF had the highest AUC for ROC curve analysis of the variable analyzed $(0.918$, CI $95 \%$ 0.892 to 0.946 ). Surprisingly, QRS duration was not independently associated with LVMD. Additionally, analysis of patients with LBBB and without significant myocardial scar (as defined as sum rest score $\leq 8$ on SPECT MPI) showed that a worsening EF was associated with increasing LVMD. In contrast, further stratification of patients by QRS duration within EF groups appeared not to impact LVMD.

One of the strengths of this study is that it attempts to address the knowledge gap surrounding the relationship of QRS duration and EF in LVMD in both LBBB and RBBB patients. Traditionally, this electrocardiographic finding has been used to support use of CRT for treatment. These findings suggest that a deeper dive might be needed to identify the truly predictive independent features. Also, the importance of myocardial 
scar is clear with its impact on ventricular remodeling and resulting LVMD. The authors should be commended for the rigorous approaches used to standardize interpretations and analysis at the individual sites. One concern for generalized use is the need to develop labspecific normals for phase analysis parameters and a question remains of how standardized this can become. In addition, future investigation would be beneficial into the effect that gender has on both patients with normal and abnormal PhaseBW and PhaseSD.

The most recent data from the American Heart Association report that an estimated 6.2 million Americans are currently being treated for varying levels of heart failure. ${ }^{13}$ The more that we can elucidate the mechanisms of the underlying pathophysiology, the greater our chances to develop novel treatment plans to bring us better "in sync", with improved clinical outcomes.

\section{Disclosures}

Neither of the authors have any disclosures to report relevant to this publication.

\section{References}

1. Epstein AE, DiMarco JP, Ellenbogen KA, Estes NA 3rd, Freedman RA, Gettes LS, Gillinov AM, Gregoratos G, Hammill SC, Hayes DL, Hlatky MA, Newby LK, Page RL, Schoenfeld MH, Silka MJ, Stevenson LW, Sweeney MO, Tracy CM, Epstein AE, Darbar D, DiMarco JP, Dunbar SB, Estes NA 3rd, Ferguson TB Jr, Hammill SC, Karasik PE, Link MS, Marine JE, Schoenfeld MH, Shanker AJ, Silka MJ, Stevenson LW, Stevenson WG, Varosy PD, American College of Cardiology F, American Heart Association Task Force on Practice G and Heart Rhythm S. ACCF/AHA/HRS focused update incorporated into the ACCF/AHA/HRS 2008 guidelines for device-based therapy of cardiac rhythm abnormalities: A report of the American College of Cardiology Foundation/ American Heart Association Task Force on Practice Guidelines and the Heart Rhythm Society. J Am Coll Cardiol 2012;2013(61):e6-75.

2. Achilli A, Sassara M, Ficili S, Pontillo D, Achilli P, Alessi C, De Spirito S, Guerra R, Patruno N, Serra F. Long-term effectiveness of cardiac resynchronization therapy in patients with refractory heart failure and "narrow" QRS. J Am Coll Cardiol 2003;42:2117-24.

3. Chung ES, Leon AR, Tavazzi L, Sun JP, Nihoyannopoulos P, Merlino J, Abraham WT, Ghio S, Leclercq C, Bax JJ, Yu CM, Gorcsan J 3rd, St John Sutton M, De Sutter J, Murillo J. Results of the predictors of response to CRT (PROSPECT) trial. Circulation 2008;117:2608-16.
4. Suffoletto MS, Dohi K, Cannesson M, Saba S, Gorcsan J 3rd. Novel speckle-tracking radial strain from routine black-and-white echocardiographic images to quantify dyssynchrony and predict response to cardiac resynchronization therapy. Circulation 2006;113:960-8.

5. Young JB, Abraham WT, Smith AL, Leon AR, Lieberman R, Wilkoff B, Canby RC, Schroeder JS, Liem LB, Hall S, Wheelan $\mathrm{K}$, Multicenter InSync ICDRCETI. Combined cardiac resynchronization and implantable cardioversion defibrillation in advanced chronic heart failure: The MIRACLE ICD Trial. JAMA 2003;289:2685-94.

6. Bax JJ, Bleeker GB, Marwick TH, Molhoek SG, Boersma E, Steendijk P, van der Wall EE, Schalij MJ. Left ventricular dyssynchrony predicts response and prognosis after cardiac resynchronization therapy. J Am Coll Cardiol 2004;44:1834-40.

7. Bax JJ, Marwick TH, Molhoek SG, Bleeker GB, van Erven L, Boersma E, Steendijk P, van der Wall EE, Schalij MJ. Left ventricular dyssynchrony predicts benefit of cardiac resynchronization therapy in patients with end-stage heart failure before pacemaker implantation. Am J Cardiol 2003;92:1238-40.

8. Sillanmaki S, Aapro S, Lipponen JA, Tarvainen MP, Laitinen T, Hedman $\mathrm{M}$, Hamalainen $\mathrm{H}$ and Laitinen $\mathrm{T}$. Electrical and mechanical dyssynchrony in patients with right bundle branch block. J Nucl Cardiol 2018.

9. Sillanmaki S, Aapro S, Lipponen JA, Tarvainen MP, Laitinen T, Hedman M, Hamalainen H, Laitinen T. Electrical and mechanical dyssynchrony in patients with right bundle branch block. J Nucl Cardiol 2020;27:621-30.

10. Azizian N, Rastgou F, Ghaedian T, Golabchi A, Bahadorian B, Khanlarzadeh V, Azizian Z, Haghjoo M. LV dyssynchrony assessed with phase analysis on gated myocardial perfusion SPECT can predict response to CRT in patients with end-stage heart failure. Res Cardiovasc Med 2014;3:e20720.

11. Henneman MM, Chen J, Dibbets-Schneider P, Stokkel MP, Bleeker GB, Ypenburg C, van der Wall EE, Schalij MJ, Garcia EV, Bax JJ. Can LV dyssynchrony as assessed with phase analysis on gated myocardial perfusion SPECT predict response to CRT? J Nucl Med 2007;48:1104-11.

12. Sillanmaki S, Gimelli A, Ahmad S, Samir S, Laitinen T, Soman P. Mechanisms of left ventricular dyssynchrony: A multinational SPECT study of patients with bundle branch block. J Nucl Cardiol 2020. https://doi.org/10.1007/s12350-020-02054-y.

13. Virani SS, Alonso A, Benjamin EJ, Bittencourt MS, Callaway CW, Carson AP, Chamberlain AM, Chang AR, Cheng S, Delling FN, Djousse L, Elkind MSV, Ferguson JF, Fornage M, Khan SS, Kissela BM, Knutson KL, Kwan TW, Lackland DT, Lewis TT, Lichtman JH, Longenecker CT, Loop MS, Lutsey PL, Martin SS, Matsushita K, Moran AE, Mussolino ME, Perak AM, Rosamond WD, Roth GA, Sampson UKA, Satou GM, Schroeder EB, Shah SH, Shay CM, Spartano NL, Stokes A, Tirschwell DL, VanWagner LB, Tsao CW, American Heart Association Council on E, Prevention Statistics C and Stroke Statistics S. Heart disease and stroke statistics-2020 update: A report from the American Heart Association. Circulation 2020;141:e139-596.

Publisher's Note Springer Nature remains neutral with regard to jurisdictional claims in published maps and institutional affiliations. 